\title{
Paleontolojik Bir Jeosit Örneği: Hasanağa Deresi, Akçadağ, Malatya
}

\author{
A Palaeontological Geosite Example: Hasanăga Stream, Akçadă̆, Malatya
}

\author{
Sibel KAYĞILI' ${ }^{1}$, Niyazi AVŞAR ${ }^{2}$, Ercan AKSOY ${ }^{1}$ \\ ${ }^{1}$ Frrat Üniversitesi, Jeoloji Mühendisliği Bölümü, Elazı̆g (skaygili@firat.edu.tr) \\ ${ }^{2}$ Çukurova Üniversitesi, Jeoloji Mühendisliği Bölümü, Adana (avsarn@cu.edu.tr)
}

\section{Öz}

Güncel veya eski bir jeolojik süreci, olayı veya özelliği ifade eden kayaç, mineral, fosil topluluğu, yap1, istif, yer şekli ya da arazi parçası jeosit olarak tanımlanır. Doğu Anadolu Bölgesinde, Malatya ili, Akçadağ ilçesinin kuzeybatısında yer alan Hasanağa Deresi boyunca yüzeyleyen bazı jeolojik birimlerde bulunan fosil topluluğunun, bu tanıma iyi bir örnek oluşturduğu görülür.

Hasanağa Deresi boyunca izlenen jeolojik birimlerin yaşları Mesozoyik’ten Kuvaterner'e kadar değişmektedir. Hasanağa Deresi boyunca Tersiyer yaşlı tortul birim çeşitliliği, Eosen yaşlı Darende Formasyonu'nun Korgantepe, Yenice ve Asartepe üyeleri, Oligosen yaşlı Muratlı Formasyonu ve Erken Miyosen yaşlı Alibonca Formasyonu ile ifade olmaktadır. Hasanağa Deresi'nde Lütesiyen'den Oligosen'e kadar uzanan düzenli istifi oluşturan birimlerde bolca bulunan ve Nummulites, Alveolina ve Discocyclina' larla temsil edilen iri bentik foraminiferler'in jeolojik miras kapsamında değerlendirilmesi bu çalışmanın konusunu oluşturmaktadır.

Hasanağa Deresi boyunca, vadinin her iki tarafında değişik boyutlu, bazılarının içinde yaşam izleri gözlenmiş olan çok sayıda mağara da bulunmaktadır. Sahip olduğu iri bentik foraminifer çeşitliliği ve bolluğu ile karstik oluşumlar ve bunlara kolay ulaşılabilirlik, bölgenin bilimsel önemini arttırmaktadır. Anahtar Kelimeler: Darende Formasyonu, Hasanağa Deresi, iri bentik foraminifer, Jeosit, Malatya. 


\section{ABSTRACT}

Rock, mineral, fossil associations, structure, geological section, landforms or a part of land which they represent current or former geological process, event or a specialty is defined geosite. Some geologic units containing fossil associations and outcropping along Hasanağa Stream located in the northwest of Akçadağ which is a settlement of Malatya city in Eastern Anatolia Region, is seen as a good example to this definition.

The age of the geological units that outcrop along Hasanağa Stream ranges from Mesozoic to Quaternary. Diversity of Tertiary sedimentary units along Hasană̆a Stream is represented by Korgantepe, Yenice and Asartepe members of Eocene Darende Formation, Oligocene Muratl Formation and Lower Miocene Alibonca Formation. The geological units constitute a regular sequence range from Lutetian to Oligocene in Hasană̆a Stream. Their abundant larger benthic foraminifera such as Nummulites, Alveolina and Discocyclina are the subject of this study and they have been evaluated within the scope of geological heritage.

Along the Hasanăga stream also, there are many caves having traces of life in some of them, on both sides of the valley, in different sizes. Diversity of larger benthic foraminifera and karstic formations increases the scientific importance of the district.

Key words: Darende Formation, Geosite, Hasană̆a Stream, arger benthic foraminifera, Malatya, Eastern Turkey.

\section{GİRIŞ}

Çalışmaya konu olan jeosit, Doğu Anadolu Bölgesi'nde, Malatya batısında bulunan Akçadağ ilçesinin kuzeybatısında yer alan Hasanağa Deresi boyunca yer almaktadır (Şekil 1, 2). Çalışma alanı yakın çevresinde, Tersiyer yaşlı birimler görülmektedir. Bunlar: Eosen yaşlı Darende
Formasyonu, Oligosen yaşlı Muratlı Formasyonu, Erken Miyosen yaşlı Alibonca Formasyonu ve Orta-Geç Miyosen yaşlı Kepezdağı Volkanitleridir.

$\mathrm{Bu}$ çalışmanın amacı bilimsel öneme sahip bu paleontolojik jeositin tanitılması ve korunmasının sağlanmasıdır. 


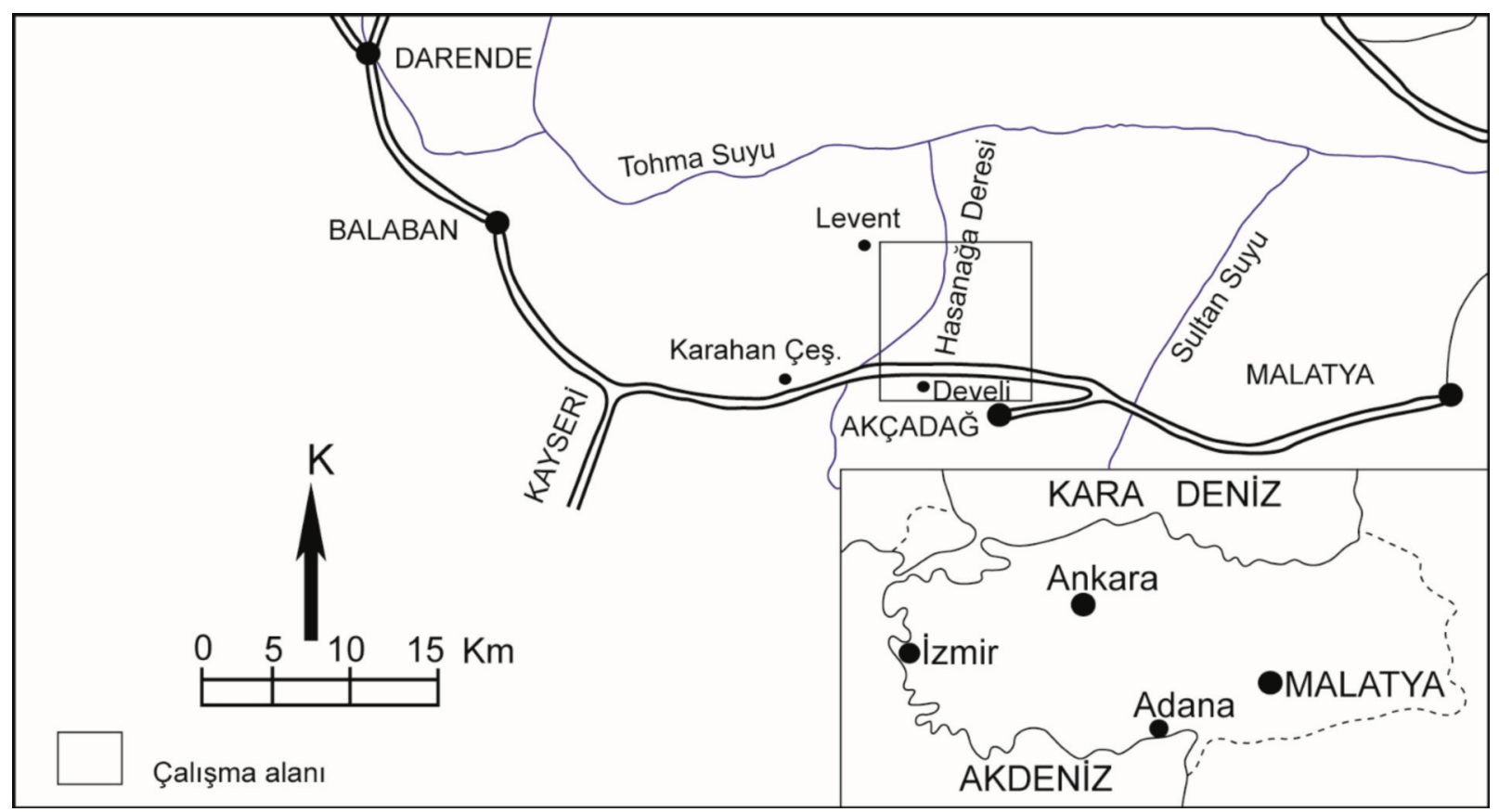

Şekil 1. Çalışma alanının yer bulduru haritası

Figure 1. Location map of the study area

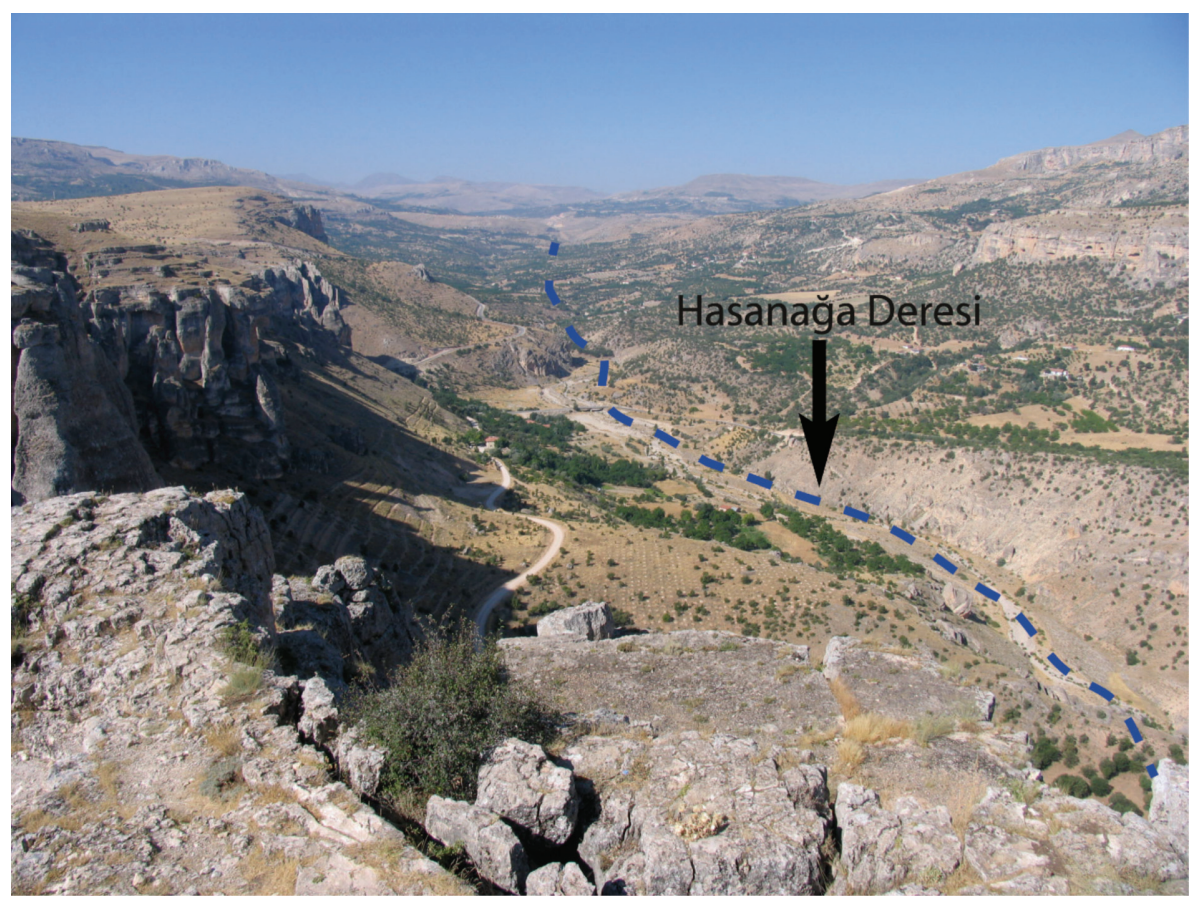

Şekil 2. Hasanağa Deresi (Bakış yönü KD)

Figure 2. Hasanağa stream (View to NE) 


\section{Paleocoğrafya}

Neotektonik, herhangi bir bölgede meydana gelmiş olan son tektonik rejim değişikliğinden günümüze kadar geçmiş olan zaman içindeki tektonizmanın tümüne denir. Türkiye'de Neotektonik dönem, Bitlis Kenet Kuşağı boyunca Anadolu ve Arap kıtalarının Orta-Geç Miyosen'den itibaren çarpışmasıyla başlamıştır. Kıtasal çarpışma geniş bir deformasyon zonu oluşturmuş olup doğuda Bitlis Zagros Bindirme Kuşağı, batıda ise Afrika Levhası'nın Anadolu Bloğu'nun altına dalması sonucu Helenik Yayı ve Kıbrıs Yayı oluşmuştur (McKenzie, 1970, 1972; Şengör, 1980; Şengör ve Yılmaz, 1981; Dewey vd., 1986). Bu çarpışma,
Geç Triyas’ta açılmaya başlayan Neo-Tetis okyanusunun kapanmasına neden olmuştur. Neo-Tetis okyanusunun güney kolunun açılması ve kapanmasının Türkiye jeolojisindeki önemi geçmişten beri bilinmekte olup bu okyanusla ilişkili birimler, söz konusu okyanusun Van-ElazığMalatya boyunca uzandığını göstermektedir. $\mathrm{Bu}$ kadar geniş bir alanda yayılım gösteren birimler, yerel farkl11ıklar göstermektedir. Kolun güneyinde geniş bir şelf söz konusu iken, kuzeyindeki şelf çok dardır ve hemen derin deniz çökellerine geçer (Şekil 3) (Perinçek, 1979; Şengör, 1980; Şengör ve Y1lmaz, 1983; Perinçek ve Kozlu, 1984; Sungurlu vd., 1985; Yazgan ve Chessex, 1991; Türkmen vd., 1999).

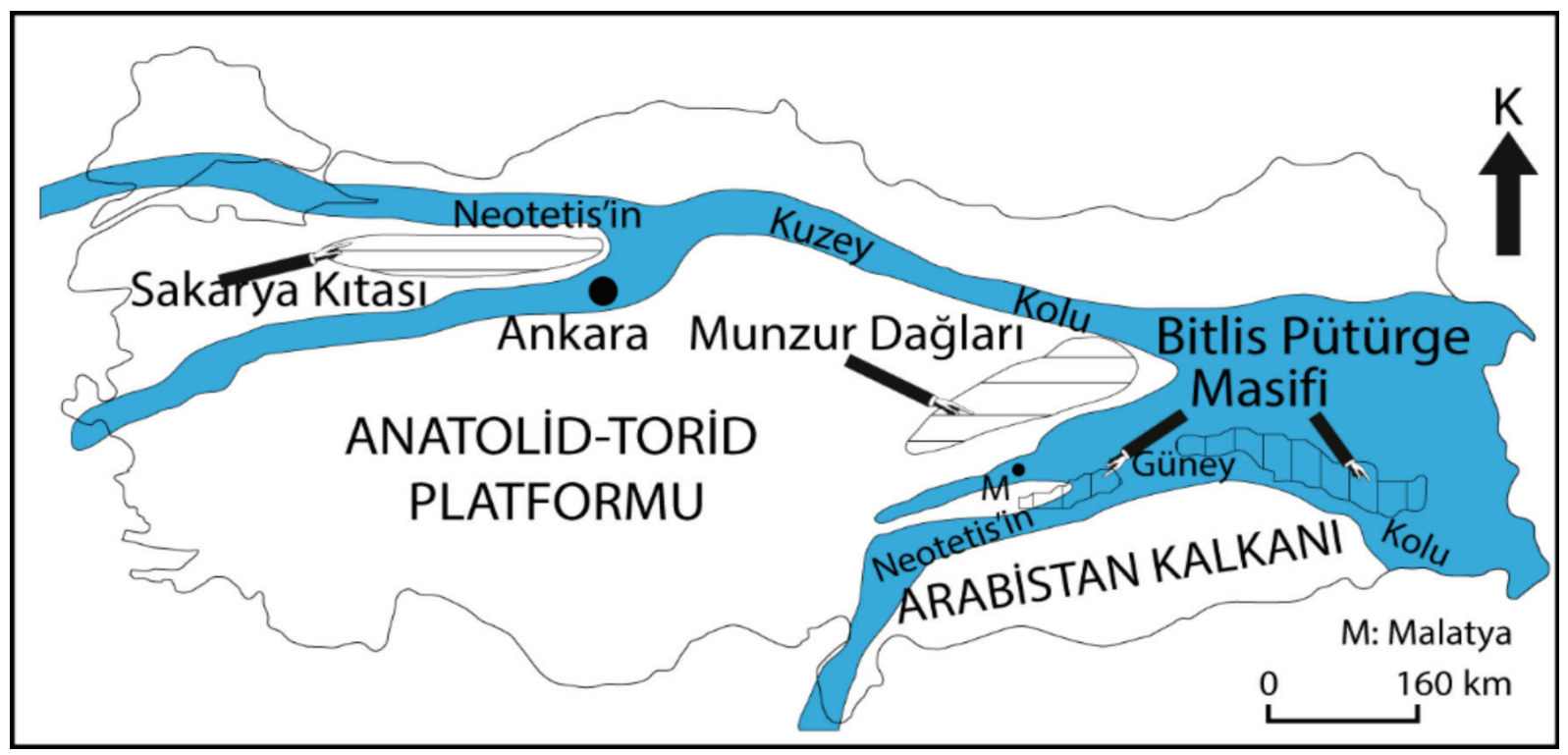

Şekil 3. Çalışma alanının (M) Neotetis Okyanusu'nun konumu içindeki yeri (Şengör ve Yılmaz, 1983; Türkmen vd., 2001'den değiştirilerek alınmıştır).

Figure 3. Position of the study area (M) within the Neotethys realm (Modified from Şengör ve Y1lmaz, 1983; Türkmen vd., 2001). 


\section{Bölgesel Jeoloji}

\section{Darende Formasyonu}

$\mathrm{Bu}$ çalışmanın konusunu oluşturan Eosen yaşlı Darende Formasyonu bölgede çalışma yapan araştırmacılar tarafından değişik isimler altında ve değişik özellikleriyle incelenmiştir. Akkuş (1971), bölgedeki Eosen yaşlı istifin tabanda Lütesiyen yaşlı Korgantepe Konglomerası ile başladığını, üzerinde Lütesiyen yaşlı Yenice Formasyonu, Asartepe Formasyonu ile Bartoniyen yaşlı Balaban Formasyonu ve Darende Formasyonu'nun yer aldığını ve bunların birbirleriyle yanal ve düşey yönde geçişli olduklarını belirtmiştir.

Malatya Havzasının Eosen yaşlı istifi Örçen (1984) tarafından Tohma Formasyonuadıyla incelenirken, Karaman vd., (1993) tarafindan Yeşilyurt Formasyonu, Çağlar (2009) tarafından ise Yeşilyurt Grubu adı altında incelenmiştir. Bedi vd., (2009) Eosen yaşl1 istifi Darende Formasyonu olarak adlandırmış ve Korgantepe, Yenice, Asartepe üyelerine ayırmışlardır. Bu adlandırma Alan (2011) tarafindan da benimsenmiştir.

Darende-Balaban Havzasındaki Eosen istifini Gürbüz ve Gül (2005) ile Dinçer ve Avşar (2012), Korgantepe Formasyonu, Yenice Formasyonu, Asartepe Formasyonu ve Darende Formasyonuna ayırarak incelemişlerdir.

Solak ve Ünlügenç (2012), Tohma Formasyonu olarak adlandırdığg Eosen yaşlı çökelleri İriağaç, Çivril, Çorak, Yoğunsakız ve Zeynepoğlu olarak 5 üyeye ayırarak incelemiştir.

$\mathrm{Bu}$ çalışmada Darende Formasyonu; Korgantepe, Yenice ve Asartepe olmak üzere üç üye halinde incelenmiştir (Şekil 4, 5).

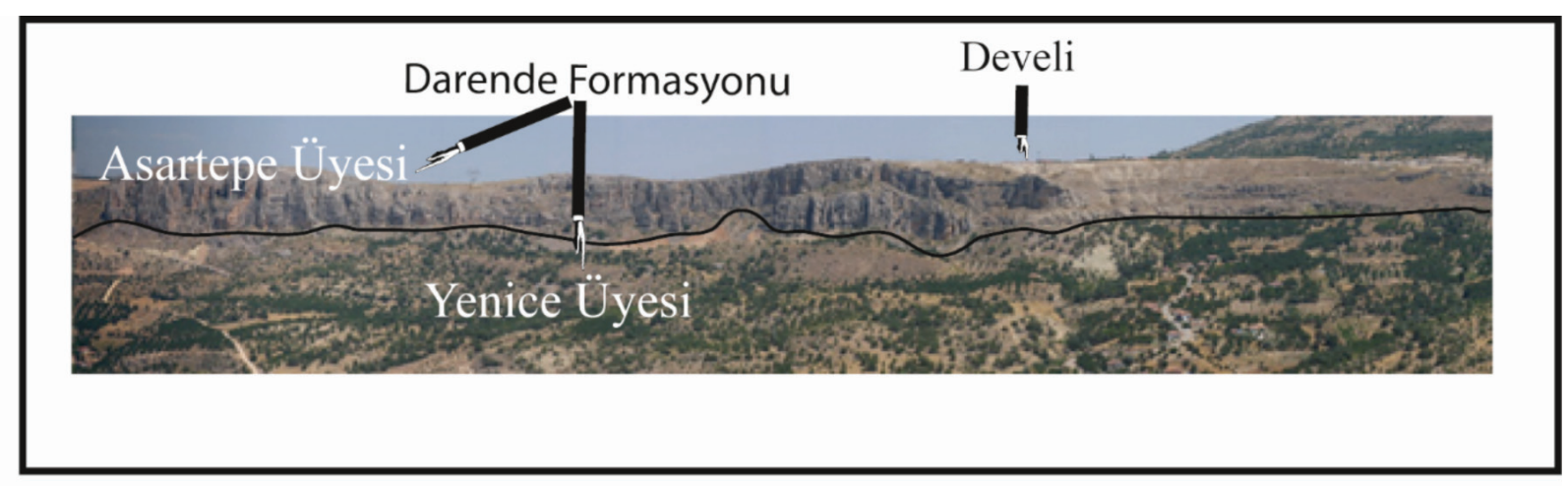

Şekil 4. Darende Formasyonu'nun Asartepe ve Yenice üyelerinin arazi görünümleri

Figure 4. Panoramic view of the Asartepe and Yenice members of Darende Formation 


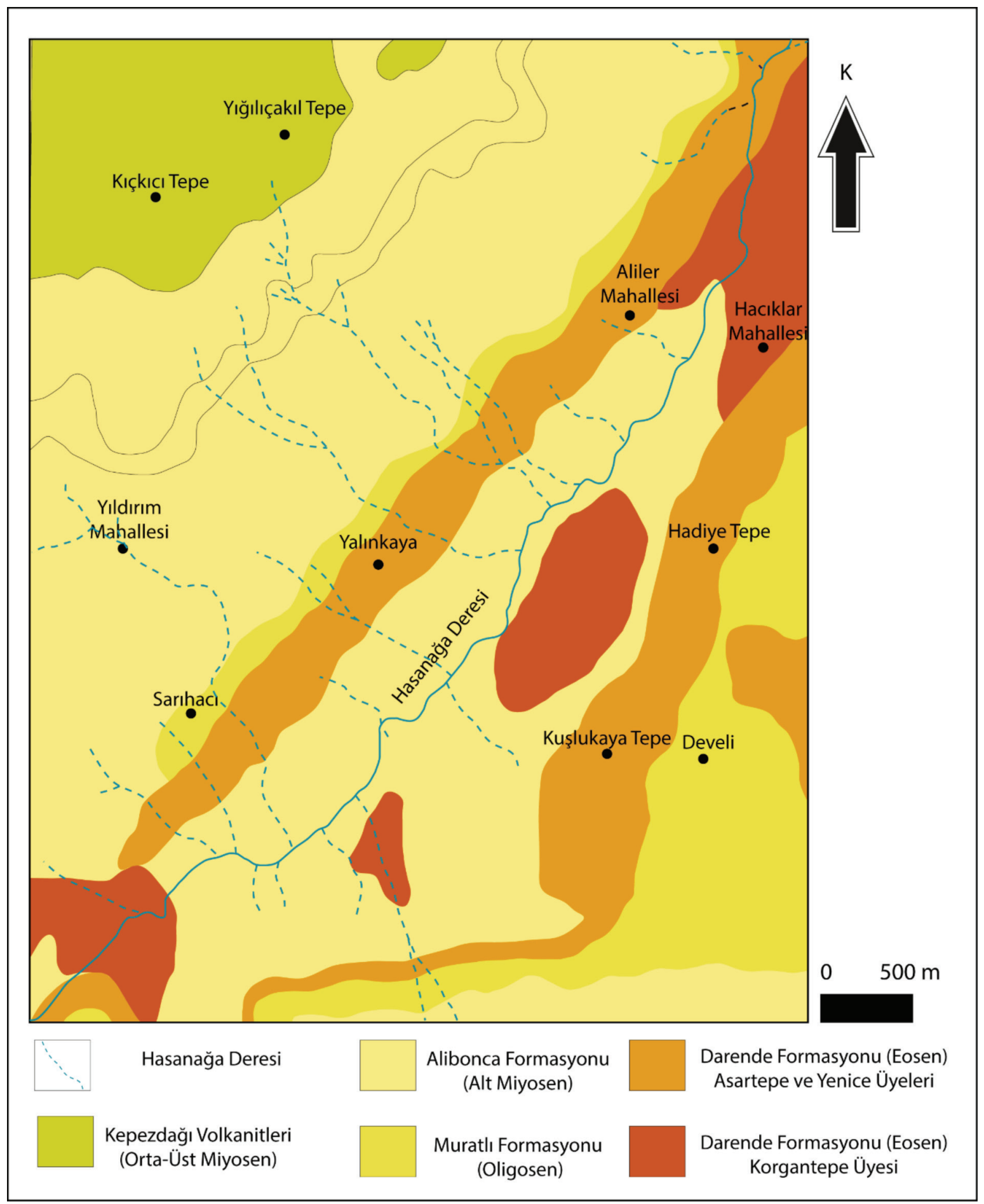

Şekil 5. Çalışma alanı ve yakın çevresinin genel jeoloji haritası (Karaman vd., 1993; Gedik, 2010 ve Alan, 2011'den değiştirilerek hazırlanmıştır).

Figure 5. Geological map of the study area and its surroundings (Modified from Karaman vd., 1993; Gedik, 20010 and Alan, 2011). 


\section{Korgantepe Üyesi}

Korgantepe Üyesi sarı, gri renkli çakıltaşı ve sarımsı grimsi renkli, ince-orta tabakalı kumtaşlarından oluşur. Çakıltaşını oluşturan çakılların boyutları 0,5-10 cm arasında değişen çört, serpantin ve volkanik kökenli olup temel kayaçlardan türemiştir. Karbonat çimentolu kumtaşlarının bileşenleri de aynı temel kayaçların ayrışma ürünüdür. Kendisini oluşturan kayaçlarda fosil bulgusuna rastlanılmayan birime stratigrafik konumu dikkate alınarak Erken Eosen yaşı verilmiştir.

\section{Yenice $\ddot{U}$ yesi}

Bol fosilli, ayrışmış killi kireçtaşlarından oluşmaktadır (Şekil 4, 7, 8). Arazide alacalı, pembemsi ve sarımsı ayrışma renkleri ile kolayca tanınır. Krem renkli olan bol fosilli, sarımsı boz renkli, ince-orta tabakalanmalı ayrışmış killi kireçtaşları; mikritik dokulu ve ince-orta tabakalıdır. Yenice Formasyonu içerisinde Geç Lütesiyen-Bartoniyen yaş aralığında; Nummulites aturicus, Nummulites beaumonti, Nummulites maximus, Nummulites perforatus, Nummulites sp.1, Nummulites sp.2, Assilina exponens, Operculina sp., Heterostegina sp., Discocyclina cf. discus, Asterocyclina sp., Praecalcarina tohmaensis, Sphaeorogypsina globula, Gypsina cf. mastelensis, Asterigerina rotula, Pararotalia sp., Neorotalia sp., Linderina brugesi, Gyroidinella magna, Halkyardia minima, Fabiania cassis, Alveolina (Alveolina) sp., Alveolina (Alveolina) cf. fusiformis, Alveolina (Alveolina) cf. fragilis, Haddonia sp., Stomatorbinid form ve Microcodium sp.'den oluşan fosil topluluğu tayin edilmiştir.

\section{Asartepe Üyesi}

Asartepe Üyesi çoğunlukla resifal kireçtaşlarından oluşur (Şekil 4). Seyrek olarak dolomitize kireçtaşları da gözlenir. Genellikle orta-kalın, belirgin tabakalanmalı ve sarımsı bej-krem renkli olan kireçtaşlarının ayrışma yüzeyi gri renkte olup oluşumundan sonra bölgeyi etkileyen tektonizmayı yansıtan ve iki ana doğrultuda gelişmiş oldukça yoğun kırıklıdır (Makaslama kırıkları). Bu kırıklar, önceki bölümde bahsedilen karstik mağaraların gelişiminde önemli rol oynamışlardır. Nummulites perforatus, Assilina exponens, Discocyclina cf. discus fosil topluluğu tanımlanmış olup Bartoniyen'de SBZ 17-SBZ 18 biyozonları tespit edilmiştir. Kesitin en üst seviyelerinde tanımlanan Pfendericonus makarskae, Orbitolites sp., Opertorbitolites sp., Spirolina sp., Pillaminid form, Miliolidae fosil topluluğu ortamın çok sığlaştı̆̆ının göstergesi olarak değerlendirilmiştir.

\section{Jeosit ve İlişkili Kavramlar}

Yerkabuğu ve onun bir parçası olan yakın çevremiz, oluşumundan bugüne kadar geçirdiği evrimi ve bu sıradaki olayların izlerini gösteren jeolojik oluşumlar bulundurur.

Güncel ve/veya eski bir jeolojik süreci, olayı veya özelliği ifade eden kayaç, mineral, fosil topluluğu, yapı, istif, yer şekli veya arazi parçası jeosit olarak tanımlanır. Jeosit, jeolojik bir özelliği temsil eden, bu özelliği görmek, öğrenmek isteyenlerin ziyaret edebilecekleri, özellikle jeoloji öğrencilerine ilgili oluşumu kolayca anlatmak için kullanılan "yer veya lokalite" anlamındadır. Boyut sinır1 yoktur. (Wimbledon, 1996; ProGeo Group, 1998; Kazanc1, 2001; Kazanc1, 2006; Kazanc1, 2010; Wimbledon ve Smith, 2012, Kazanc1 vd., 2015). 
Malatya Havzasındaki Eosen yaşlı Darende Formasyonu'nun içerdiği iri bentik foraminiferler, bu tanım kapsamındaki oluşumlar olarak değerlendirilmiş ve bunların bulunduğu alan bilimsel öneme sahip ve yerbilimi eğitimi amacıyla kullanılabilecek bir jeosit olarak önerilmiştir.

Hasanağa Deresi boyunca, vadinin her iki tarafında değişik boyutlarda, bazılarının içinde yaşam izleri de gözlenmiş olan çok sayıda mağara bulunmaktadır. Bu mağaralar Asartepe Üyesi’nin masif kireçtaşlarındaki karstlaşma sonucu oluşmuştur. Bölgedeki yoğun tektonizmaya bağlı olarak gelişen kırıklar karstlaşmayı kolaylaştırmıştır. Söz konusu mağaralardaki insan faaliyetlerinin yaşlandırılabilmesi halinde önemlerinin daha da artacağı bir gerçektir. Uzanımı boyunca yer aldıkları Hasanağa Deresi vadisi hem karstik mağaraların hem de iri bentik foraminiferlerin görülebileceği bir jeolojik rota olarak da düşünülebilir.

\section{Materyal ve Metod}

Bu çalışma, Hasanağa Deresi boyunca yüzeyleyen Eosen yaşlı Darende Formasyonu'nun Yenice ve Asartepe üyelerinden ölçülü stratigrafik kesitler boyunca alınan tane örneklerden yönlü kesit, sert kayaçlardan da yönlü ince kesit yapılması ve bunların paleontolojik incelenmesi şeklinde gerçekleştirilmiştir. İnceleme sonucunda, bu örneklerin alındığı (Şekil 6) yerlerde iri bentik foraminiferlerin bol bulunduğu ortaya konulmuş ve bu alanların paleontolojik jeosit tanımına uygun olduğu anlaşılmıştır.

\section{Hasanağa Deresi Nummulitleri}

Çalışma alanından alınan örnekler incelenmiştir. Bunun sonucunda; Geç Lütesiyen'de Assilina exponens, Nummulites aturicus, Nummulites beaumonti, Nummulites maximus ve Discocyclina cf. discus, Erken Bartoniyen de Alveolina (Alveolina) cf. fragilis, Alveolina (Alveolina) cf. fusiformis, Planorbulina cf. bronnimanni, Fabiania cassis, Halkyardia minima, Gyroidinella magna, Gypsina cf. mastelensis, Sphaerogypsina globula, Assilina exponens, Asterigerina rotula, Nummulites beaumonti, Nummulites maximus, Nummulites perforatus, Operculina sp., ve Discocyclina cf. discus, Geç Bartoniyen'de Planorbulina cf. bronnimanni, Fabiania cassis, Halkyardia minima, Gyroidinella magna, Gypsina cf. mastelensis, Sphaerogypsina globula, Asterigerina rotula, Operculina sp., tayin edilmiştir. Tanımlanan fosil içeriğinden yararlanarak bazı zonlar tanımlanmıştır. Örneğin sı ğ bentik foraminiferlerin baskın olduğu yerleri ve belirli bir yaş aralığını belirtmek üzere sığ bentik zon anlamında SBZ kisaltması ve arkasından yaş aralığını belirten bir sayı kullanılır. Bu çalışmada tanımlanan bentik türlerin stratigrafik dağılımlarından yararlanarak; Geç Lütesiyen'de SBZ 16, Erken Bartoniyen'de SBZ 17 ve Geç Bartoniyen'de SBZ 18 zonu belirlenmiştir. Şekil 9'da bu zonlara ait bazı bentik foraminiferlerin mikroskobik görüntüleri verilmiştir.

Sahip olduğu iri bentik foraminifer çeşitliliği ve bolluğu bölgenin bilimsel açıdan önemini arttırmaktadır. $\mathrm{Bu}$ jeolojik oluşum ve yapılara sahip alanın bir diğer avantajlı yanı kolay ulaşılabilir olmasıdır. Hasanağa Deresi boyunca yer alan bu bölge, sahip olduğu özelliklere bağl1 olarak bilimsel öneme sahip bir jeosit olarak tanımlanmıştır. 


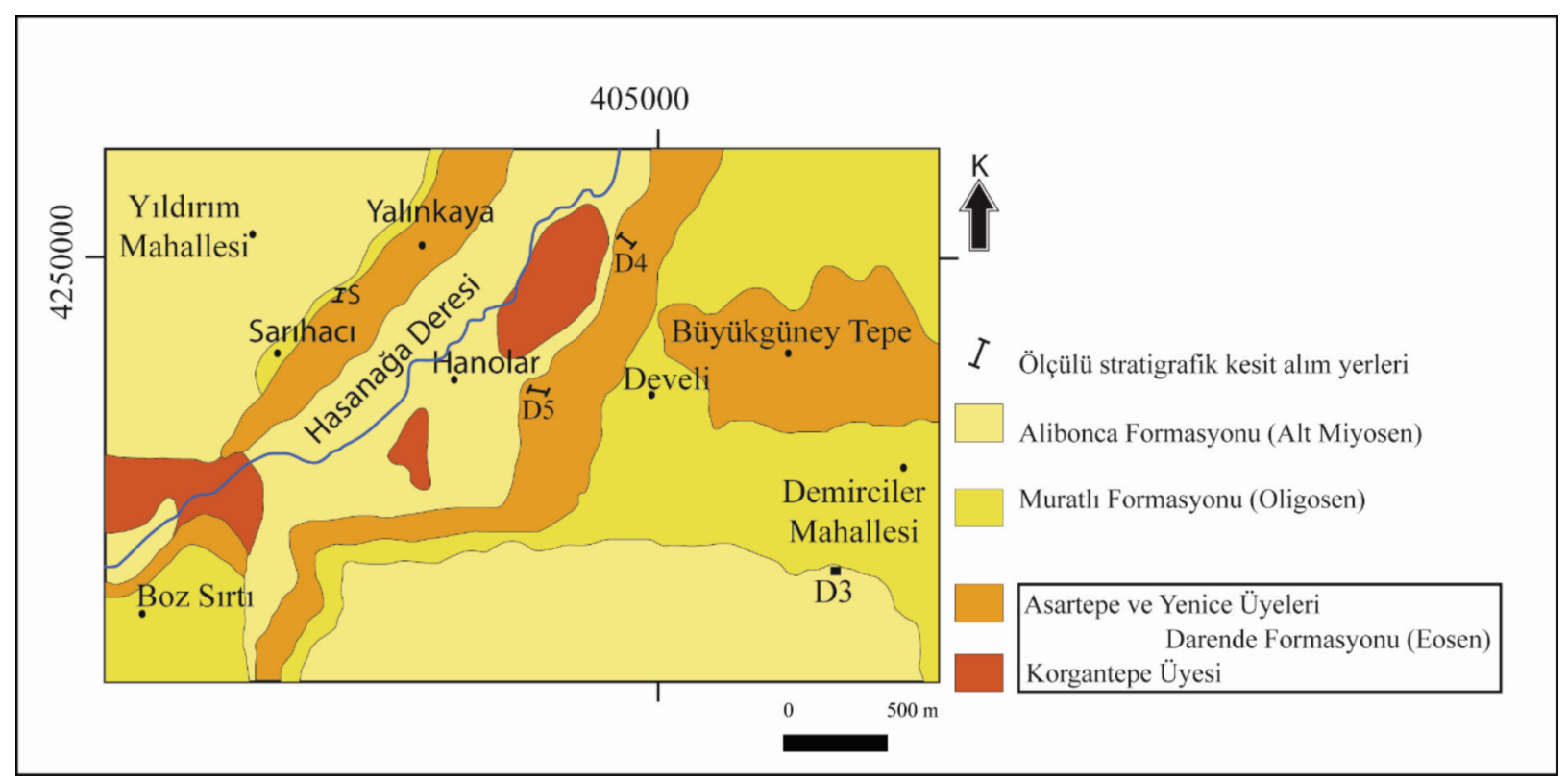

Şekil 6. İ̉i Nummulites' in bulunduğu yerler (D4, D5)

Figure 6. Location of larger Nummulites (D4, D5)

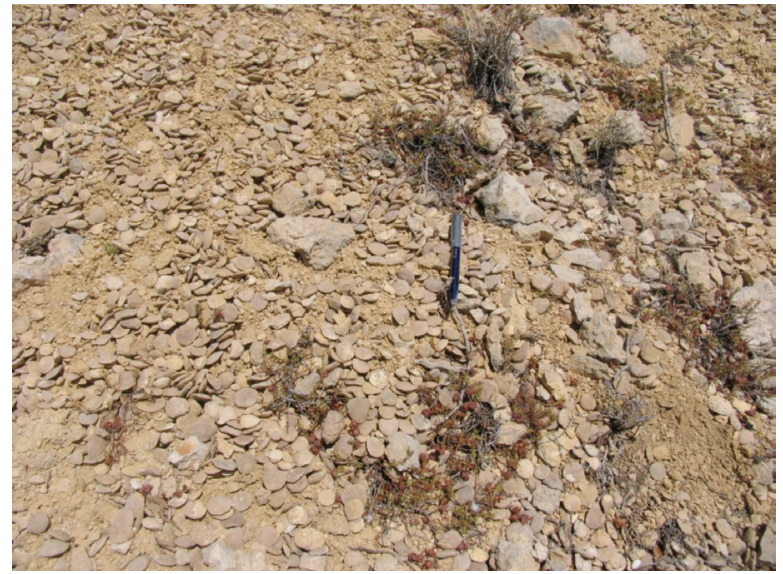

Şekil 7. Darende Formasyonu'nun Yenice Üyesi içerisindeki Nummulites fosilleri

Figure 7. Nummulites fossils in Darende Formation's Yenice member

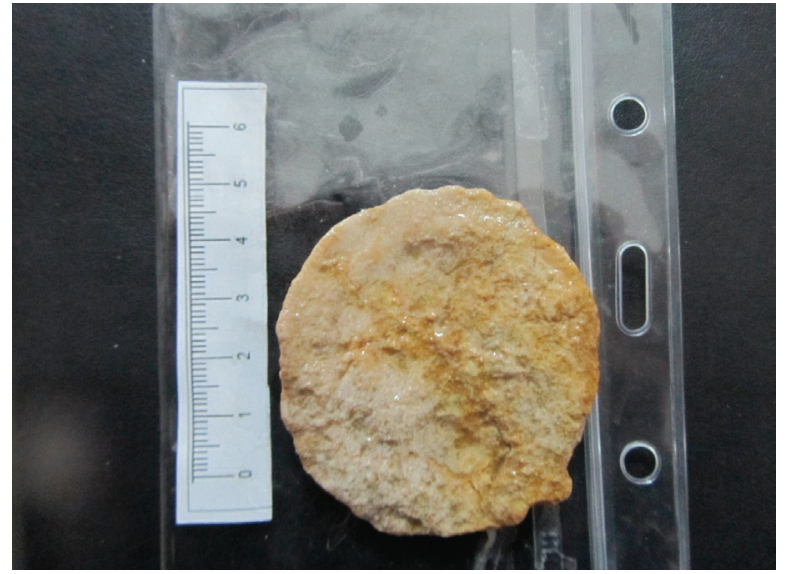

Şekil 8. İ̀i Nummulites' in görünümü

Figure 8. View of larger Nummulites 


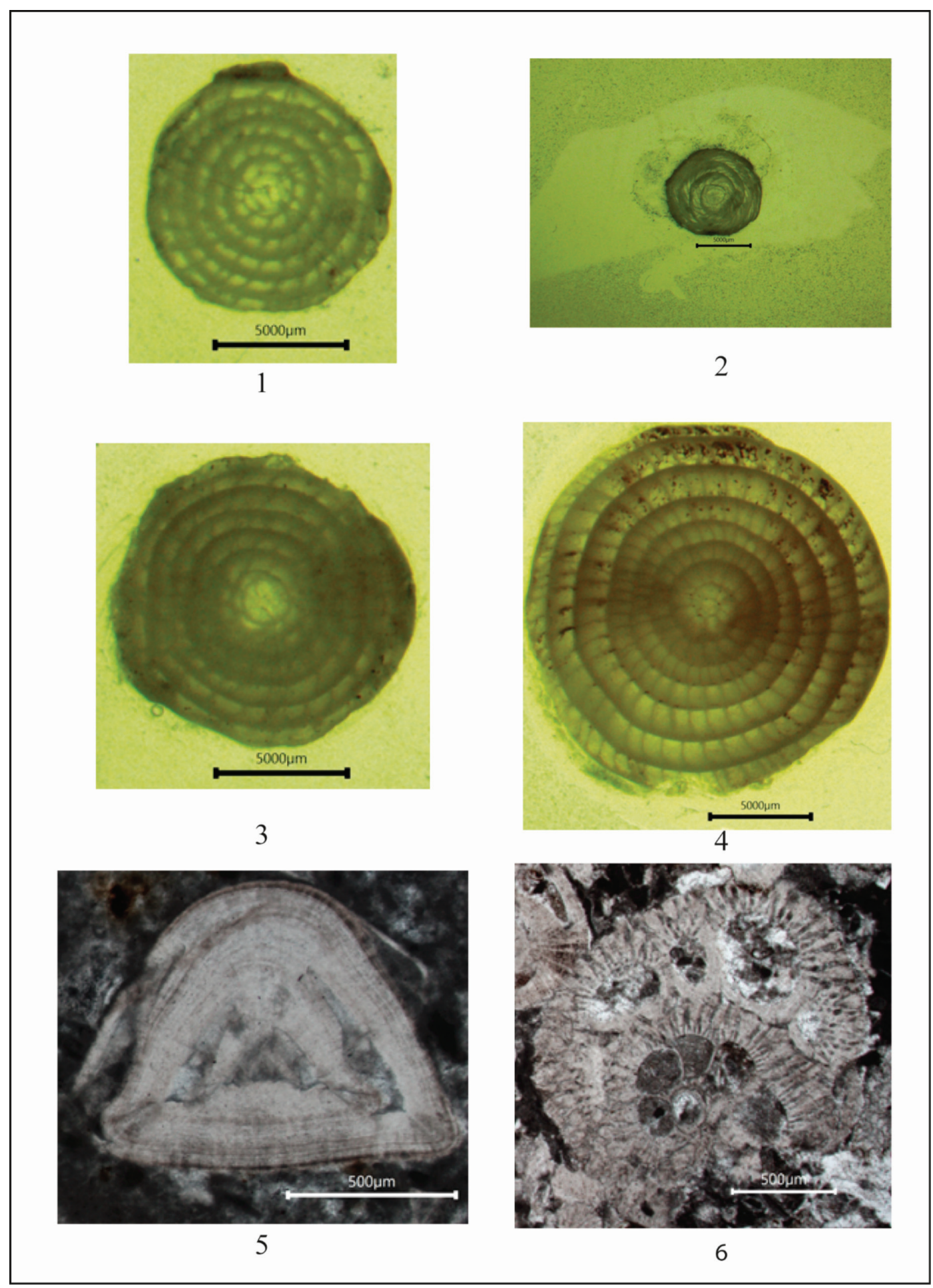

Şekil 9. Fosillerin mikroskobik görünümleri: 1- Nummulites aturicus 2- Nummulites maximus 3- Nummulites perforatus 4- Assilina exponens 5- Asterigerina rotula 6- Gyroidinella magna

Figure 9. Microscopic views of fossils: 1- Nummulites aturicus 2- Nummulites maximus 3- Nummulites perforatus 4- Assilina exponens 5- Asterigerina rotula 6- Gyroidinella magna 


\section{SONUÇLAR VE ÖNERILER}

Paleontolojik çalışmalar sonucunda, Hasanağa Deresi nummulitlerinin bölgenin jeolojik evriminin anlaşılmasını sağlayan doğal belge niteliğinde olduğu ortaya konulmuştur. $\mathrm{Bu}$ durum ile iri bentik foraminifer çeşitliliği ve bunların sayısal bolluğu jeositle ilgili kavramlar kapsamında değerlendirildiğinde, Hasanağa Deresi vadisinin bu fosillerin yer aldığ1 bölümlerinin bilimsel açıdan önemli ve korunması gereken bir paleontolojik jeosit olduğu sonucuna varılmıştır. Fosil görülen her lokasyon elbette bir jeosit değildir. Ancak bu çalışma alanı yukarıda da açıklandığı gibi Nummulites fosillerinin ender örneklerini içermektedir. Bu fosil örnekleri ve söz konusu vadi boyunca yer alan ve bazılarında insan faaliyet izlerinin de bulunduğu karstik oluşumlu mağaralar birlikte değerlendirildiğinde, Hasanağa Deresi vadisi bir jeolojik rota olarak da düşünebilir.

\section{KATKI BELIRTME}

$\mathrm{Bu}$ çalışma TÜBİTAK $115 \mathrm{Y} 035$ nolu proje ile desteklenmektedir. TÜBİTAK'a teşekkür ederiz. Bu çalışmada laboratuvar çalışmalarında ve paleontolojik yorumlamalarda yardımını esirgemeyen Sayın Dr. Şükrü ACAR'a teşekkürü borç biliriz.

\section{EXTENDED SUMMARY}

Geosite is the basis and integral part of geologic protection, geo-diversity, geo-park and geologic heritage. Geosites are the important natural formations at national and international levels, such as rock units, stratigraphic sequence, fossil, mineral, geologic structure and characteristic landform formations. In other words, geologic formations that cannot be encountered everywhere and that represents a definite process, event, time or result, are documents belonging to the past of earth crust. Since Digne Declaration in 1991, it has been well understood that the earth has a right to convey its own created values and especially geosites to the future.

When considering this definition, some geologic units containing fossil associations and outcropping along Hasanağa Stream located in the northwest of Akçada $\breve{g}$ which is a settlement of Malatya in Eastern Anatolia Region, is seen as a good example to this definition.

The age of the geological units that outcrop along Hasanağa Stream ranges from Mesozoic to Quaternary. Tertiary units are mapped as Korgantepe, Yenice and Asartepe members of Eocene aged Darende Formation, Oligocene aged Muratl Formation and Early Miocene aged Alibonca Formation. These units are indicative of the diversity of Tertiary sedimentary units along Hasanağa Stream. The outstanding importance of the region is to have Eocene large benthic foraminifera diversity. The geological units of a regular sequence range from Lutetian to Oligocene in Hasanağa Stream contain large benthic foraminifera which the most abundant forms are represented by Nummulites, Alveolina and Discocyclina.

A further advantage of the region having this geological formation and structure is being easily accessible. This region, which is located along Hasanağa Stream, has been identified as a geosite depending on its characteristics. Along the Hasanăga stream also, there are many caves having traces of life in some of them, on both sides of the valley, in different sizes. Diversity 
of larger benthic foraminifera and karstic caves increases the scientific importance of the district. Both of these features gain a geological route characteristic to Hasanağa Stream valley.

Just as people have a right to get and use the heritage from their ancestors, the earth also has the same right to include geosites that are the products of its own geologic past and to protect these as a heritage. Within this context, Hasană̆a Stream Nummulites is one of the significant paleontological geosites of the earth.

\section{DEĞIINILEN BELGELER}

Akkuş, F. M., 1971. Darende-Balaban havzasındaki (Malatya, DGD anadolu) litostratigrafik birimler ve jipsli formasyonların yaşı hakkında yeni bilgiler. Maden Tetkik ve Arama (MTA) Dergisi, 75, 1-18.

Alan, B., 2011. Malatya Havzasındaki sığ denizel sedimanların Eosen (Orta- Geç Eosen) bentik foraminifer tanımlaması ve biyostratigrafisi. Ankara Üniversitesi Fen Bilimleri Enstitüsü, Ankara, Doktora Tezi, 249s (yayınlanmamış).

Bedi, Y., Yusufoğlu, H., Beyazpirinç, M., Usta, D., Özkan, M.K., Yıldız, H. 2009. Doğu torosların jeodinamik evrimi. MTA derleme No: 11150 (yayımlanmamış).

Çağlar, M., 2009. Benthic foraminiferal biostratigraphy of the tertiary sediments from the Elazig and Malatya Basins, Eastern Turkey. Journal of the Geological Society of India, 74, Issue 2, 209-222.

Dewey, J.F., Hempton, M.R., Kidd, W.S.F., Şaroğlu, F. and Şengör, A.M.C., 1986. Shorteninig of continental lithosphere: The tectonics of eastern Anatolia: A young collision zone. Collision tectonics, 19, 3-36.

Dinçer F. ve Avşar N, 2012. Darende Havzası (KB Malatya) Üst Lütesiyen- Bartoniyen birimlerinin bentik foraminifer biyostratigrafisi ve ortamsal yorumu. Haccettepe Üniversitesi Yerbilimleri Dergisi, 33, 31-58.

Gedik, F., 2010. Malatya havzasındaki sığ denizel sedimanların Oligo-Miyosen bentik foraminifer tanımlaması ve biyostratigrafisi, Ankara Üniversitesi, Fen Bilimleri Enstitüsü, Ankara, Doktora Tezi, $177 \mathrm{~s}$.

Gürbüz, K. ve Gül, M., 2005. "Evolution of and factors controlling Eocene sedimentation in the DarendeBalaban basin, Malatya (Eastern Turkey)", Turkish Journal of Earth Sciences, 14, 311-335.

Karaman, T., Poyraz, N., Bakırhan, B., Alan, İ., Kadınkız, G., Yılmaz, H. ve Kılınç, F. 1993. Malatya-Doğanşehir-Çelikhan dolayının jeolojisi. MTA Raporu No: 958, Ankara (yayımlanmamış).

Kazanc1, N., 2001. Jeolojik miras üzerine, Mavi Gezegen, 4, 4-9.

Kazanc1, N., 2006. Jeoparklar ve nitelikleri: Geçmişten geleceğe yanık ülke. Kula Sempozyumu, 1-3 Eylül 2006 bildiriler, Kula, 78-81.

Kazanc1, N., 2010. Jeolojik koruma kavram ve terimler. Jeolojik mirası koruma derneği yayını, 60s.

Kazanc1, N., Şaroğlu, F. ve Suludere, Y., 2015. Jeolojik miras ve Türkiye jeositleri çatı listesi, 151, 263272.

McKenzie, D.P., 1970. Plate tectonics of the Mediterranean region, Nature, 220, 239-343.

McKenzie, D.P., 1972. Active tectonics of Mediterranean region, Geophys. J.R., Ast. Soc., 30, 109-185.

Örçen, S., 1984. Medik-Ebreme (KB Malatya) dolayının biyostratigrafisi ve paleontolojisi. İstanbul Üniversitesi Fen Fakültesi, İstanbul, Doktora Tezi, 68s.

Perinçek, D., 1979. The geology of Hazro-KorudağÇüngüş-Maden-Ergani-Hazar-Elazığ-Malatya area. Guide book, Türkiye Jeoloji Kurumu Yayını, $33 \mathrm{~s}$. 
Perinçek, D. and Kozlu, H. 1984. Stratigraphy and structural relations of the units in the AfşinElbistan-Doğanşehir region (Eastern Taurus). Geology of Taurus Belt, O. Tekeli, M. C. Göncüoğlu (Eds), Türkiye Petrolleri Anonim Şirketi, Ankara, 181-198.

ProGeo Group, 1998. A first attempt at a geosites framework for Europe an IUGS initiative to support recognition of world heritage and European geodiversity. Geologica Balcanica, 28, 5-32.

Şengör, A.M.C., 1980. Fundamentals of neotectonics of Turkey: TJK Conference, Ser. 2, 40p.

Şengör, A.M.C. ve Yilmaz, Y., 1981. Tethyan evolution of Turkey; a plate tectonic approach. Tectonophysics, 75, 181-241.

Şengör, A.M.C. ve Yılmaz, Y., 1983. Türkiye'de Tetis'in evrimi: Levha Tektoniği açısından bir yaklaşım. Türkiye Jeoloji Kurultayı (TJK), Yerbilimleri özel dizisi, 1 .

Solak, S. ve Ünlügenç, U.C, 2012. Levent (AkçadağMalatya Batıs1) ve civarının tektono-stratigrafisi. Çukurova Üniversitesi Fen ve Mühendislik Bilimleri Dergisi, 27(4), 122-130.

Sungurlu, O., Perinçek, D., Kurt, G., Tuna, E., Dülger, S., Çelikdemir, E. ve Naz, H., 1985. Elazı̆̆Hazar-Palu alanının jeolojisi. Petrol İşleri Genel Müdürlüğü Dergisi, 29, 83-191.
Türkmen, İ., İnceöz, M. ve Kerey, İ. E., 1999. Kırkgeçit Formasyonu (Orta Eosen-Oligosen) gelgit düzlüğü ve firtınalı şelf kompleksine bir örnek (Elazığ KKB's1), Yerbilimleri Bülteni, 21, 125-142.

Türkmen, İ., İnceöz, M., Aksoy, E. ve Kaya, M., 2001. Elazı̆̆ yöresinin Eosen stratigrafisi ve paleocoğrafyası ile ilgili yeni bulgular. Haccettepe Üniversitesi Yerbilimleri Bülteni, 24, 81-95.

Wimbledon, W. A. P., 1996. National site election, a stop on the road to a European geosite list, Geologica Balcanica, 26, 15-27.

Wimbledon, W. A. P., Smith-Meyers, S., 2012. Geoheritage in Europe and its conservation ProGEO special publications, Oslo, Norway, 405s.

Yazgan, E., and Chessex, R., 1991. Geology and tectonic evolution of the southeastern taurides in the region of Malatya. Türkiye Petrol Jeologları Derneği Bülteni, 3, 1-42.

$\begin{array}{ll}\text { Makale Geliş Tarihi } & : 1 \text { Temmuz } 2016 \\ \text { Kabul Tarihi } & : 16 \text { Aralı } 2016 \\ \text { Received } & : \text { 1 July 2016 } \\ \text { Accepted } & : \text { 16 December } 2016\end{array}$


